\title{
UNA INNOVACIÓN CONTESTADA LA IMPLANTACIÓN DEL CARGO DE ALFÉREZ MAYOR EN TIERRAS VALENCIANAS*
}

\author{
María del Carmen IRLES VICENTE \\ Universidad de Alicante
}

Tras el decreto de Nueva Planta los ayuntamientos valencianos fueron remodelados tomando como base el modelo castellano'; sin embargo, algunas de las prácticas habituales en Castilla, tales como la enajenación de empleos públicos ${ }^{2}$, fueron proscritas desde el primer momento en el área de la Corona de Aragón. En este sentido cabe destacar que cuando el conde de Bureta, regidor decano de Zaragoza, solicitó el oficio de alférez mayor de esta ciudad con carácter perpetuo, la Cámara no dudó en representar al monarca, en Consulta de 11 de enero de 1716, que:

"aunque el conde era digno de las honras y favores de V.M., así por el lustre de su casa - que es de las primeras de Aragón-, como por el sumo celo y amor con que procedió en las pasadas turbaciones, pérdidas de su hacienda y dilatada prisión que padeció en Barcelona, era la Cámara de parecer excusase V. M. la concesión de esta gracia por los inconvenientes que se podían seguir"3.

La recomendación de la Cámara fue atendida por Felipe V, quien se limitó a indicar al conde "que pusiese los ojos en otra cosa". Aunque la misma actitud de rechazo a conceder la perpetuidad de los empleos públicos se evidenció en diferentes momentos a lo largo del primer tercio del siglo ${ }^{4}$ a finales de la década de los treinta, y como consecuencia de la crisis hacendística existente, se tomó la determinación de poner en venta las regidurías y otros empleos subalternos comprendidos en el ámbito de la Corona de Aragón, tanto con carácter vitalicio como perpetuo por juro de heredad'5. 
Coincidiendo con las enajenaciones de 1739-41 hizo su aparición en el ámbito municipal valenciano un nuevo cargo de carácter honorífico: el alférez mayor.

A mediados de 1740 el setabense Tomás Cebrián remitió un memorial a la Cámara solicitando una regiduría con carácter perpetuo y facultad para nombrar teniente, a cambio de la cual ofrecía 16.000 rls. Aunque esta petición fue aprobada, poco después daba marcha atrás en su pretensión al entender que la plaza que se le concedía no era la segunda en vacar, como él creía, sino la tercera ${ }^{7}$.

Aunque descartó la idea de adquirir una regiduría, no abandonó su proyecto de entrar a formar parte del ayuntamiento; de ahí que a principios de 1741 formulara el deseo de obtener el cargo de alférez mayor. Para lograr este objetivo no se limitaba, como hiciera en 1740, a ofrecer una determinada cantidad de dinero, ya que en esta ocasión al ofrecimiento en metálico añadía los servicios que en favor de la monarquía, y más concretamente en defensa de los derechos de Felipe $\mathrm{V}$ al trono español, habían realizado sus parientes más allegados.

Su padre, José Cebrián, había sido encarcelado por los partidarios del Archiduque, quienes, no conformándose con semejante vejación, habían saqueado, asimismo, su casa. También su abuelo, Félix Cebrián, fue desterrado de la ciudad de Valencia durante el enfrentamiento sucesorio por su fidelidad al borbón, lealtad que sería recompensada en ambos casos con la concesión de sendas regidurías en la primera planta municipal ${ }^{8}$. Además de este cargo José Cebrián obtuvo, como compensación a las pérdidas sufridas, 3.000 pesos en bienes confiscados, los cuales hubo de reintegrar como consecuencia de las capitulaciones de la Paz de Viena de $1725^{\circ}$.

Además de los méritos de sus ascendientes más directos, refería también los de Juan Crisóstomo Berenguer y Bartolomé Sanchiz, bisabuelo y tatarabuelo paternos, los cuales habían desempeñado diferentes empleos, y entre ellos el cargo de oidor en la Audiencia foral. También Martín y Juan de Terrasas, bisabuelo y tatarabuelo por línea materna, habían sobresalido en defensa de la monarquía, si bien esta vez en empleos militares, llegando a obtener el grado de teniente general ${ }^{10}$.

Junto a los méritos de su familia figuraba el ofrecimiento de 20.000 rls., de ahí que José de Bustamante no encontrara reparo en acceder a la petición que Cebrián hacía del

"nuevo empleo de alférez mayor de dicha ciudad de San Felipe, con todos los honores y preeminencias a él anexos en los reinos de Castilla, y con los gajes, salarios, honores y emolumentos pertenecientes a un regidor de dicha ciudad, y voz y voto en su ayuntamiento, por juro de heredad para sí y sus sucesores, con facultad de servirle por teniente"11.

Aunque por lo general se aceptaba sin más el contenido de los memoriales que pretendían un empleo por servicio pecuniario, en este caso Tomás Cebrián hubo de justificar documentalmente cada uno de los extremos referidos en su exposición para lograr la aprobación regia 12 . 
La inexistencia de este tipo de cargos en los municipios de la antigua Corona de Aragón - "en los reinos de la Corona de Aragón es este oficio de alférez mayor para la ciudad de San Felipe el primero que se ha creado13"'- suscitó las dudas de Francisco Campo de Arbe sobre los términos en que debía ser redactado el correspondiente título. El modelo de referencia fue el concedido en 1649 a Pedro García de Requena, alférez mayor de la villa de Bogarra.

Las cláusulas que regulaban las competencias y prerrogativas del empleo hacían referencia tanto a su vertiente política como a la militar, destacando en ambos casos su carácter honorífico y preeminente.

Los privilegios de carácter gubernativo ponían especial énfasis en la asistencia al consistorio, lugar de asiento dentro del mismo, así como en los atributos o insignias con los que podía concurrir a él, los cuales le diferenciaban del resto de capitulares, ya que, por ejemplo, le permitían entrar "con armas de espada y daga":

"tengáis en el Ayuntamiento voz y voto activo y pasivo, y todas las otras preeminencias, honras y facultades que tienen y tuvieren los regidores (...); tengáis en el ayuntamiento de ella asiento y voto, y el mejor y más preeminente lugar, delante de todos los regidores, aunque sean más antiguos, de manera que después de la Justicia tengáis el primer voto y mejor lugar, lo cual sea y se entienda así en los (...) ayuntamientos, como en los actos de recibimientos y procesiones y otros cualquier donde la Justicia y regimiento fuere y se ayuntaren, y llevéis de salario en cada un año lo mismo que llevan cada uno de los regidores" 14 .

En el terreno militar su misión consistía en la dirección de las compañías armadas que se formasen a cargo de la propia ciudad en caso de enfrentamientos bélicos:

"cuando la dicha ciudad o villa me sirviere con gente de a caballo y de a pie, en cualquier manera y para cualquier efecto que sea para mi servicio, seáis alférez de la tal gente, y hayáis y llevéis el sueldo y salario de tal alférez, según el tiempo que hubiere y conviniere dar por la dicha ciudad (...), y allende del salario ordinario que por razón de ser regidor se da y lleva".

Además de los aspectos reseñados también disponía del privilegio de enarbolar el pendón en las proclamaciones regias y demás ocasiones que lo requiriesen:

"vos y el teniente que habéis de nombrar saquéis y llevéis y alcéis el penđón de la dicha ciudad al tiempo que se alzare por mí y por los reyes que después de mí sucedieren en estos Reinos, y en los otros días que se suele y acostumbra sacar";

así como guardar en su domicilio los símbolos representativos de la ciudad: 
"tengáis en vuestro poder los atambores, banderas, pendones y otras insignias que se suelen y acostumbran tener".

Las cláusulas anteriores eran las habituales en los títulos de alférez mayor, sin embargo, a la hora de redactar el de Cebrián se dudó sobre la conveniencia de incluir estas últimas, ya que en el Reino estaba prohibida la leva de gentes y el uso de armas $y$, por tanto, confiar a un particular ${ }^{15}$, aunque distinguido, dichas insignias podía producir algún inconveniente. Finalmente este reparo fue descartado e incluida dicha cláusula en el título; sólo se innovó en cuanto a la indumentaria o complementos que debería llevar para asistir a cabildo, señalándose en este sentido que "entréis en él con las armas correspondientes al uso y traje regular que se practique" 16 .

La pretensión de Cebrián de obtener un cargo que gozaba de preeminencia sobre el resto de capitulares, y que hacía perder al regidor decano sus tradicionales prerrogativas, fue visto con malos ojos por los ediles setabenses desde el primer momento, de ahí la oposición desencadenada por parte de los mismos para impedir que la enajenación se llevara a efecto ${ }^{17}$. Los argumentos esgrimidos por los regidores hacían referencia a diferentes ámbitos. En primer lugar denunciaron el gravamen que supondría para el presupuesto de la ciudad la creación de un nuevo cargo; también la falta de tradición del mismo, tanto en San Felipe como en el conjunto de la Corona de Aragón, fue considerado un inconveniente.

$\mathrm{Al}$ problema económico se añadían los conflictos de precedencia que en el consistorio ocasionaría la entrada de "un joven de pocos años", que sólo reunía la condición de ciudadano, y que estaría colocado por encima de títulos del Reino como el duque de Berwick o el marqués de Grimaldo, el teniente general Patricio Laules o el propio Tobías de Burgo ${ }^{18}$.Los argumentos expuestos por el Ayuntamiento no fueron tenidos en cuenta en la Corte, por lo que una vez consolidada la venta, y como ocurriera con el resto de empleos enajenados durante el bienio 1739-41, los regidores vitalicios intentaron consumir dicho empleo, a lo que contestó Cebrián diciendo que éste no era susceptible de tanteo por haber sido concedido no tanto por ofrecimiento en metálico, cuanto por "méritos y servicios, y en recompensa de daños experimentados por haber mantenido la debida fidelidad a V.M."19.

Todos los capitulares, con la única excepción de Antonio José Cebrián, pariente del alférez mayor, manifestaron su disposición a aprontar los 20.000 rls. desembolsados en su día por Tomás Cebrián, si bien este ofrecimiento no era a fondo perdido, ya que tenían intención de recuperar dicha cantidad "cuando los efectos de la ciudad lo permitan"20.

Básicamente los argumentos esgrimidos por los capilulares setabenses para fundamentar su recurso al tanteo eran los efectos negativos del cargo sobre la hacienda municipal, tanto por "el salario, gajes y emolumentos" que conllevaba, como por los litigios que se habían suscitado como consecuencia de las prerrogativas que su propietario se atribuía. Además dicho cargo era calificado como "empleo de ningún beneficio ni precisión para el gobierno". 
Pese a las diferentes peticiones formuladas por los regidores, un decreto de 25 de mayo de 1743 zanjó momentáneamente la cuestión al sentenciar no haber "lugar por ahora al tanteo que pide la ciudad de San Felipe"; las razones, como en toda decisión regia, quedaban sin aclarar, aunque probablemente fueran consecuencia del enorme endeudamiento de la hacienda municipal y de la negativa de quienes pretendían acometer dicho tanteo a satisfacerlo de sus propios bolsillos.

$* * *$

San Felipe fue el primer municipio valenciano en contar con un alférez mayor al frente de su ayuntamiento, pero no sería el último, ya que hacia 1745 tanto en Orihuela como Jijona aparecieron sendos individuos interesados en lograr idéntico cargo. También en esta ocasión se unían servicios personales y pecuniarios para fundamentar el supuesto derecho al mismo.

En el caso de la capital de la Vega Baja, dicho empleo lo obtuvo Gaspar Cebrián, alcalde del crimen de la Audiencia valenciana, para que lo desempeñara su yerno Ignacio Sánchez Belmont, previo pago de 30.000 rls.

Gaspar Cebrián de Cebrián, primo por línea materna del primer alférez mayor de San Felipe ${ }^{21}$, alegó los méritos de ambas ramas de la familia de este apellido. Por línea materna destacó los servicios de Félix Cebrián y sus antepasados, a los que ya hicimos referencia al tratar del alferazgo de San Felipe; no eran inferiores, sin embargo, los de la rama paterna, donde tanto sus tíos Francisco Cebrián como Juan Ortiz - casado con Isabel Cebrián - sufrieron saqueos en sus tierras por haber abandonado casa y hacienda para seguir las tropas de Felipe $V$, razón por la que fueron recompensados con sendas regidurías en el primer ayuntamiento borbónico. Peor suerte sufrió su padre, Gaspar Cebrián, quien, tras servir como sustituto del lugarteniente de tesorero general de la ciudad, durante el conflicto sucesorio fue preso por los austracistas y sufrió el saqueo de sus bienes, lo que acabó ocasionándole la muerte:

"por mantener la fidelidad a Su Majestad fue preso por las armas del Señor Emperador en la cárcel pública, donde, y a muchos de su familia, los tuvieron después por algunos meses en rigurosa prisión en el castillo; y que era voz pública que Baret (sic) quería mandarle dar garrote por su afecto a $\mathrm{Su}$ Majestad, y con efecto hizo poner horca y cadalso diciendo había de acabar y extinguir la familia de los Cebrianes de Játiva, habiéndole deteriorado y saqueado su hacienda, lo que fue motivo de su fallecimiento"22.

La fidelidad durante la Guerra de Sucesión y los múltiples servicios en favor de la monarquía realizados por Gaspar Cebrián y sus antepasados, unidos al ofrecimiento pecuniario - que superaba en 10.000 reales al que abonara su primo en $174 \mathrm{I}$ - , llevaron a Felipe V a aprobar la creación del cargo de alférez mayor en la ciudad de Orihuela. El 28 de septiembre de 1745 se expidió a Ignacio Sánchez 
Belmont y Adán el título que le acreditaba como tal, y a primeros de noviembre tomaba posesión del mismo.

No duró mucho, sin embargo, la tranquilidad de Belmont, ya que pocos meses después de incorporarse al cargo descubrió que los capitulares aspiraban a tantearlo. Sin perder un momento recurrió al monarca destacando en su exposición que aquél no había sido concedido únicamente a cambio de una determinada cantidad de dinero, sino como recompensa a los servicios prestados, por lo que de querer consumir los oficios enajenados con carácter perpetuo debían comenzar por las regidurías; también achacaba a "envidia y conjuración" la actitud de los ediles oriolanos.

Para zanjar rápidamente el tema Belmont pidió que se declarara "por intanteable el citado empleo de alférez mayor", o cuanto menos que lo fuera durante la vida del actual propietario.

La creencia de que una solicitud acompañada de un ofrecimiento en metálico tendría mejor acogida que una petición lisa y llana, llevó a Ignacio Sánchez a ofrecer 3.000 rls. a cambio de obtener la seguridad de que dicho cargo no iba a ser tanteado.

No sólo la familia de su esposa había tenido una actuación encomiable durante el enfrentamiento sucesorio: en este sentido D. Ignacio podía presentar los méritos de su padre, Juan Belmont, designado justicia mayor de Orihuela en 1707 por el virrey Belluga, o los suyos propios, fruto de su permanencia en el ejército durante 14 años como cadete y alférez de dragones, hasta que por pérdida de su salud obtuvo la correspondiente cédula de preeminencias militares.

Para actuar con mayor conocimiento de causa, y como venía siendo habitual en temas de esta naturaleza, desde la Corte se pidió informe a la Audiencia valenciana sobre la conveniencia de aceptar la solicitud de Belmont, la que a su vez lo trasladó al Ayuntamiento de Orihuela.

La opinión estaba dividida entre los capitulares oriolanos, pues mientras Ramón Malla, José González Ampuero y Joaquín Timor eran fervientes partidarios de erradicar el empleo de alférez mayor del consistorio, el resto -Diego de Soto, José Maseres y Miguel Angel Azor - lo eran de que continuase al menos hasta que las arcas municipales estuvieran mejor surtidas de numerario ${ }^{23}$, y siempre y cuando recayese en "persona distinguida y benemérita", condiciones que cumplía sobradamente D. Ignacio. Pequeñas divergencias entre estos últimos propiciaron que los tres primeros fueran mayoría en el cabildo que se celebró a mediados de septiembre de 1746 para informar sobre la solicitud formulada por Belmont ${ }^{24}$.

Creemos interesante comentar sucintamente cuáles fueron los inconvenientes que los regidores oriolanos atribuían al empleo de alférez mayor y que les impulsaron a emplear la fórmula del tanteo para erradicarlo del consistorio.

En primer lugar destacaban la falta de tradición del cargo, que no sólo no había existido durante la época foral, sino que tampoco se había instaurado tras la asimilación al modelo castellano, a partir de 1707. Además apuntaban que "la novedad que no llama a la corrección de algún abuso siempre trae inconvenientes"25. 
En segundo lugar, señalaban que al regidor decano correspondía el primer asiento, firma y enumeración de propuestas en el ayuntamiento; así como el derecho a levantar pendones y ejercer la jurisdicción en ausencia, enfermedad y vacantes del gobernador y alcalde mayor. El puesto de regidor decano, el de mayor antigüedad en el ayuntamiento, se conseguía en función de las vacantes que fueran produciéndose, pero con la aparición del alférez mayor las prerrogativas de aquél desaparecían al ser asumidas por éste. De aquí surgían inconvenientes a la Monarquía, a la Ciudad, y a los propios capitulares, ya que no aspirarían al cargo de regidor "las personas más calificadas, más aptas y de más servicios del pueblo, y en el defecto del mejor gobierno que se debe esperar de estas calidades, ninguno padecería más que S.M. como padre, rey y dueño de sus pueblos y vasallos".

La cláusula de perpetuidad presente en el título de alférez mayor también podría ser causa de serios conflictos de recaer el cargo en sujeto no cualificado, sobre todo si llegaba el caso de tener que dirigir la defensa de la ciudad -"pudiera ser el poseedor del oficio tan fuera de propósito para el peculiar manejo de las armas y dirección de la gente de guerra"-.

Resultaba también contraproducente, según los capitulares, que tanto el corregidor o alcalde mayor como el alférez llevaran como signo distintivo el bastón, pues "además de que parece representación de jurisdicción mixta, disuenan dos bastones $y$ dos cabezas en un cuerpo, llevando el gobernador o alcalde mayor, por justicia del rey, la misma insignia".

Tampoco podría llegar a desempeñar con la misma capacidad que el regidor decano el resto de funciones públicas que tenía encomendadas, ya que la mayor antigüedad en cl cargo se consideraba como garantía de una mejor actuación. ${ }^{26}$

La situación de la hacienda municipal -"falta de medios para sus alimentos y pago de acreedores de justicia"- parecía desaconsejar la creación de un nuevo empleo, que llevaría aparejado un nuevo salario, así como las exenciones y emolumentos inherentes al resto de capitulares.

La implantación del cargo de alférez mayor era en perjuicio de terceros, ya que los regidores perdían la posibilidad de alcanzar las prerrogativas que les hubieran correspondido en caso de llegar a decanos del ayuntamiento, ventajas con las que pudieron contar en el momento de obtener sus empleos, ya que no existía cl cargo de alférez mayor.

Por otro lado afirmaban que si Belmont había recibido el empleo en recompensa de servicios, no eran menores los de Orihuela -"ciudad cabeza de pariido, segunda del Reino, piedra que resplandece por servicios y méritos entre las grandes"- o los del conjunto de capitulares, de donde se infería que aquél no tenía por qué usurpar unos derechos que eran inherentes a ćstos.

Un último detalle puesto de manifiesto por los capitulares oriolanos era la nulidad de la posesión dada a Sánchez Belmont en noviembre de 174l. Según éstos, sólo cuatro regidores componían el ayuntamiento en la sesión de 7 de noviembre de 1745 cuando se presentó aquél a jurar su cargo, los cuales, "sin convocación ante diem, 
como está mandado por saludables providencias del rey, sin salvedad de derechos, y sin más consideración que el celo de obedecer, le dieron la posesión".

Aparte de las consideraciones expuestas hasta aquí, los capitulares oriolanos añadían que la obtención del carácter de intanteable solicitado por Belmont iba en contra de lo dispuesto por Felipe V en su decreto de 10 de noviembre de 1741, así como lo establecido últimamente por Fernando VI en decreto de 21 de agosto de 1746, "pues no se podrían consultar las vacantes no siendo el sucesor a propósito en otros que lo fuesen, manteniendo este oficio intanteable con perpetuidad".

Adelantaban, asimismo, que tenían intención de solicitar que se extinguiese el oficio de alférez mayor "sin que esta república ni otro común ni particular tenga que padecer el menoscabo de suplir el servicio"; sin embargo, y por dudar que se aceptara sin más dicha petición, añadían que se reservaban el derecho de tanteo "para hacerle por sí, sus regidores o común, cómo y cuándo convenga".

La solicitud de tanteo no se hizo esperar, ya que en cabildo de 4 de diciembre, y por tres votos contra dos, se acordó asignar los sobrantes del pósito de granos para consumir empleo tan negativo. Votaron a favor del tanteo Ramón Malla, José González Ampuero y Joaquín Timor, y en contra Diego de Soto y Miguel Angel Azor; este último fundó su negativa en lo exhausta de caudales que se hallaba la ciu$\mathrm{dad}^{27}$, argumento que, junto al de haber sido concedido más en remuneración de servicios que por aporte pecuniario, sería también utilizado por Belmont y su suegro para intentar inclinar al monarca en su favor ${ }^{28}$.

La disparidad de opiniones en el consistorio y en la Audiencia -donde el alcalde del crimen Cebrián se decantaba por los supuestos derechos de su yerno, mientras el fiscal lo hacía en favor del tanteo- llevaron a ésta a no emitir informe colegiado como se le había pedido desde la Corte, limitándose a presentar los documentos aportados por cada una de las partes.

Sánchez Belmont fundaba su solicitud de que no se pudiera tantear el oficio de alférez mayor en ser ésta la norma habitual en Castilla - - la nueva pretensión de que se exima este oficio de ser tanteado es tan conforme a la práctica de los empleos de Ayuntamientos de los Reinos de Castilla que son muy raros (en especial en las Andalucías) los que no tienen esta preeminencia"29-, y deber aplicarse en Valencia por haber sido trasplantadas a tierras valencianas las leyes castellanas - "estando los Reinos de la Corona de Aragón, desde la abolición de los fueros, sujetos a las leyes de Castilla, también deberán gozar sus pueblos y vasallos las preeminencias que los castellanos"-

El fiscal de la Audiencia, por su parte, hacía especial hincapié en lo dispuesto en el quinto género de condiciones de Millones, donde se prevenía repetidamente que no se vendieran "los oficios de regidores, veinticuatros, alféreces mayores ni otros que tengan voz y voto en los ayuntamientos de las ciudades, villas y lugares", así como que "los vendidos y acrecentados se vayan consumiendo, como fueren vacando, hasta dejarlos en el número que tenían el año 1540, y que las mismas ciudades, villas y lugares puedan tantearlos y consumirlos"; 30 este argumento era contestado 
por Belmont al señalar que la condición 25 de millones de las Cortes de 1650 no afectaba en absoluto a este caso por referirse a empleos antiguos, en tanto que el suyo era de reciente creación.

Finalmente, y visto el informe del fiscal del Consejo, la Cámara consultó al monarca sobre la oportunidad de extinguir dicho empleo, aunque manteniendo a su titular como regidor del ayuntamiento, para lo cual bastaría con que la Ciudad le reintegrase los 10.000 rls. pagados en exceso respecto al precio en que habían sido enajenadas las regidurías en dicho municipio. El lugar y asiento a ocupar por Belmont en el consistorio sería el que "como regidor le tocare en su clase, y entrando en el número de los seis de ella cuando le toque" 31 .

El rey se conformó con los argumentos expuestos por la Cámara, de ahí que el 7 de junio de 1747 extinguiera el empleo de alférez mayor de Orihuela, y pocos días después, concretamente el 20, se expidiera a Ignacio Sánchez título de regidor. Pese a la resistencia de los regidores a darle posesión — "aparte del perjuicio a la Ciudad en el aumento de su sueldo, se deja conocer la disonancia de este ejercicio y goce $\sin$ que aguarde su turno"32-, ya que no existían vacantes, Belmont pasó a formar parte del Ayuntamiento a partir de septiembre de dicho año.

$* * * * *$

Hasta el momento nos hemos referido a los casos de San Felipe y Orihuela, pero aún hubo otra ciudad valenciana en la que estuvo a punto de introducirse dicho cargo, si bien no llegó a materializarse por el enfrentamiento que desde un primer momento surgió por la titularidad del mismo.

En enero de 1746 se recibió en la Corte el memorial de Joaquín Aracil solicitando el cargo de alférez mayor de la ciudad de Jijona. Como ya ocurriera en los dos casos citados con anterioridad, los argumentos utilizados para inclinar en su favor el ánimo del monarca eran los servicios prestados por su familia en época foral y, sobre todo, durante el conflicto sucesorio, a más de un ofrecimiento en metálico.

Mariano Aracil, padre del solicitante, había desempeñado el empleo de baile de Jijona desde 1692 a 1707, momento en el que por establecerse las leyes de Castilla había desaparecido dicho cargo.

La fidelidad demostrada por la familia Aracil durante el enfrentamiento sucesorio había sido, asimismo, notoria, ya que tanto Mariano Aracil, padre del pretendiente al alferazgo, como Diego, hermano de aquél y tío de éste, habían servido como capitanes de milicias y habían acudido en socorro del castillo de Jijona - abasteciéndolo con "harina, carneros, balas y demás municiones"- cuando lo sitiaron los enemigos, además de contribuir con su dinero al rescate de algunas personas amenazadas de muerte por los austracistas. Posteriormente, y tras la caída de Jijona en poder de los seguidores del Archiduque, Mariano Aracil abandonó su "casa, hacienda y conveniencias", trasladándose a territorio bajo control borbónico. Como premio a su actuación en la Guerra de Sucesión Diego obtuvo una plaza en el primer ayun- 
tamiento de regidores; sin embargo, la muerte privó a Mariano de lograr un cargo de esta naturaleza o cuanto menos una recompensa económica sobre bienes confiscados.

Por supuesto, a los méritos familiares anteriores Aracil añadía el ofrecimiento de 400 pesos, a la vez que señalaba que la creación de este cargo no iba a suponer ningún gravamen para la ciudad, ya que al carecer de salario el empleo de regidor, no supondría ningún perjuicio para la hacienda municipal.

La solicitud de Aracil fue contestada rápidamente por uno de los regidores jijonencos, el más afectado por la presunta creación de este cargo, por tratarse del decano. Leonardo García mostró su disconformidad con que se concediera el alferazgo a Aracil porque en este caso tendría preeminencia sobre el resto de regidores independientemente de la condición social de los mismos. García, que contaba con el privilegio de hidalguía, se quejaba de que si la petición prosperaba sería precedido de un mero ciudadano.

Pese a la contradicción formulada por García, la Cámara consultó favorablemente la petición de Aracil y el monarca la aprobó. ${ }^{33}$ El nulo resultado obtenido por la representación del decano le llevó a emprender otras medidas como la de mostrarse aspirante al citado cargo, si bien pujando más alto, ya que ofrecía 600 pesos. No fue únicamente una oferta monetaria más cuantiosa la baza que jugó García para obtener el cargo de alférez mayor. Como hicieron el resto de pretendientes a semejante empleo, los méritos familiares ocupaban un importante lugar a la hora de fundamentar su solicitud.

Leonardo era hijo del capitán de milicias Francisco García, un ferviente seguidor de la causa borbónica, a la que se incorporó a finales de 1704. Francisco no sólo abandonó casa y hacienda, sino que participó en la recuperación de la ciudad de Játiva y las villas de Relleu, Onteniente, Alcoy, Denia; en socorro de las fronteras de Villena, Elda, Biar y Bañeres; en el sitio de Alicante; en la defensa y recuperación de Jijona... Todas estas acciones le sirvieron de catapulta para desempeñar empleos superiores como teniente de corregidor de Pedro Corbí, o regidor a partir de noviembre de 1709 .

Como consecuencia de su militancia proborbónica sufrió "gran pérdida y menoscabo en sus bienes y hacienda, robándole y saqueándole sus muebles, frutos y ganados, cuyo menoscabo se regula por cinco mil pesos"34.

Además de los méritos de su padre, D. Leonardo puso especial énfasis en su parentesco con el mariscal de campo Diego de Cárdenas, padre de su mujer.

Consideraciones económicas y jurídicas llevaron a la Cámara a cambiar de parecer e inclinarse por García como candidato más idóneo para la plaza de alférez mayor. En electo, éste poseía un status superior a Aracil, ya que su padre había obtenido privilegio de hidalguía en febrero de $1713^{35}$.

Sin embargo, y vista la contradicción existente, el monarca consideró oportuno pedir informe al ayuntamiento jijonenco sobre las ventajas o inconvenientes que la creación de este nuevo cargo podía ocasionar. Como ya sucediera en San Felipe y 
Orihuela, también en esta ocasión el consistorio se encontró dividido entre partidarios (Marcos Berdú, Tomás Soler) y detractores de dicho empleo (Vicente Picó, Justino Garrigós, Valeriano Bernabeu) -"expresando tres regidores que no conviene alférez mayor, y dos que no se seguiría inconveniente de su creación"-- Quienes se mostraron conformes fundamentaron su postura en que dicha creación serviría para repartir las cargas que hasta el momento tenían asignadas los regidores, a la vez que no supondría ningún gravamen para la Ciudad por no tener dotación salarial. Los inconvenientes apuntados por la parte contraria fueron los mismos que ya se habían señalado en los dos ayuntamientos que contaban con este cargo, al que se añadía uno particular, ya que la defensa del castillo de Alicante corría de su cuenta:

"esta ciudad, en atención a su fidelidad, goza de un privilegio concedido por el Señor D. Felipe V (...) en el que le concedió la custodia y guarda del castiIlo de la ciudad de Alicante (...) en caso de peligro, y está en la posesión de nombrar dicha ciudad oficiales (capitán, teniente, alférez) cuando Su Majestad (...) manda vaya gente de esta ciudad para la custodia del expresado castillo".

Fue precisamente este argumento el que inclinó a la Cámara a pronunciarse contra la creación de semejante empleo para evitar las discordias entre regidores y alférez mayor por la dirección de dichas milicias:

"aunque en todos los ayuntamientos es conveniente la paz y unión para el buen ejemplo de sus vecinos, en este de Jijona se necesita más particularmente, excusándose cualquiera motivo de discordia, pues le está encomendado el acudir con las milicias de sus vecinos al socorro en las ocasiones de rebatos que ocurran en aquellas costas, y también a guarnecer el castillo de Alicante en caso de necesidad; y como el alférez mayor por sus preeminencias podría pretender el comando de esta milicia de vecinos en semejantes lances, que siempre son urgentes, considera la Cámara que lo más seguro es evitar cualquiera embarazo que entre el alférez mayor y los regidores pueda haber" 36 .

Por otro lado, parece que los enfrentamientos entre las familias García y Aracil por cuestiones de precedencia no eran nuevas, y que ésta había sido una de las razones que habían movido a Francisco García a dejar de asistir al ayuntamiento hacia 1712, pues en su opinión se le había hecho notorio agravio al nombrar a Diego Aracil como primer regidor cuando debía haberlo sido él37.

米柬水

Aunque en su dictamen de 9 de marzo de 1747 el fiscal del Consejo se mostró partidario de acabar con todos 
"Ios oficios de alférez mayor que hubiese beneficiados en las ciudades particulares de aquel Reino, y los demás de la Corona, a excepción de las capitales, en beneficio de sus respectivos ayuntamientos, para que les sirviesen sus regidores decanos, o por lo menos que no se les prive del derecho que tienen a ello y para tantearles cuando y como les convenga",

sólo se puso en práctica dicha medida por lo respectivo a las ciudades de Orihuela y Jijona, ya que San Felipe siguió contando con un alférez mayor preeminente pese a los reiterados intentos de acabar con el mismo emprendidos por su ayuntamiento a lo largo de todo el XVIII.

\section{NOTAS}

:Este trabajo ha sido realizado gracias a la concesión de una ayuda a la investigación por parte de la I.V.E.I.

1.- Novisima Recopilación de las Leyes de España, libro III, título III, ley I. Madrid, 1976.

2.- TOMÁS Y VALIENTE, F., "Origen bajomedieval de la patrimonialización y la enajenación de oficios públicos en Castilla", en Actas del I Symposium de Historia de la Administración, Madrid, 1970, pp. 125-159. Id., "Las ventas de oficios de regidores y la formación de oligarquías urbanas en Castilla (siglos XVII y XVIII)", en Actas de las I Jornadas de Metodología Aplicada a las Ciencias Históricas. Santiago de Compostela, 1973, III, pp. 551-568. DOMÍNGUEZ ORTIZ, A., "La venta de cargos y oficios públicos en Castilla y sus consecuencias económicas y sociales", en Anuario de Historia Económica y Social $\mathrm{n}^{\circ} 3$ (1970), pp. 105-137.

3.- A.H.N. Consejos. Leg. 18.333. Consulta de la Cámara de Castilla, 20 de noviembre de 1730.

4.- Pese a que el Dr. José Arboleda, Casimiro García, Luis Lombardón y Tomás Vidal solicitaron sendas regidurías en los ayuntamientos de Orihuela y Alicante con carácter perpetuo previa entrega de alguna cantidad en metálico, todas las ofertas fueron rechazadas. Cfr. A.H.N. Consejos. Leg. 18.333 y Leg. 18.344.

5.- IRLES VICENTE, M.C., "Política y hacienda. La enajenación de regidurías en los municipios valencianos cabeza de corregimiento", en FORTEA PÉREZ, J.I. y CREMADES GRIÑÁN, C.M. (eds.), Política y Hacienda en el Antiguo Régimen. Actas de la II Reunión Cientifica de la Asociación Española de Historia Moderna, vol. I. Murcia, 1993, pp. 323-332.

6.- A.H.N. Consejos. Leg. 18.250. Consulta de la Cámara de Castilla, 10 de oclubre de 1740.

7.- A.H.N. Consejos. Leg. 18.250. Francisco Campo de Arbe a Pedro Díaz de Mendoza, Madrid, 21 de marzo de 1746.

8.- Las regidurías correspondían a la ciudad de San Felipe en el caso del padre, y de Valencia en el de Félix Cebriân.

9.- PRADELLS NADAL, J., Del foralismo al centralismo. Alicante, 1700-1725. Alicante, 1984, p. 234. 
10.- A.H.N. Consejos. Leg. 18.250. Memorial de Tonás Cebrián y Linas de Terrasas.

11.- Ibidem.

12.- A.H.N. Consejos. Leg. 18.250. Consulta de 17 de abril de 1741.

13.- A.H.N. Consejos. Leg. 18.250. Francisco Campo de Arbe a Francisco Javier Morales. Madrid, 11 de julio de 1741 .

14.- A.H.N. Consejos. Leg. 18.250. Sobre el empleo de alférez mayor de la ciudad de San. Felipe en el Reino de Valencia concedido a D. Francisco Cebrián. Madrid, 19 de julio de 1741.

15.- Sobre el tema GIMÉNEZ LÓPEZ, E., "Un aspecto de la normalización política en la Valencia borbónica. El cambio de legislación sobre el uso de armas", en Anales Valentinos $\mathrm{n}^{\circ} 31$ (1990), pp. 119-127.

16.- A.H.N. Consejos. Leg. 18.250. Título de alférez mayor a Tomás Cebrián. San IIdefonso, 30 de julio de 1741 .

17.- Sólo Antonio José Cebriá y Joaquín Jiménez se mostraron contrarios a representar al monarca sobre los inconvenientes de la creación del cargo de alférez mayor. Cifr. A.H.N. Consejos. Leg. 18.250. Testimonio dado por Luis Meliana sobre el Cabildo que se celebró el 4 de julio de 1741.

18.- A.H.N. Consejos, Leg. 18.250. Representación del Ayuntamiento de San Felipe. San Felipe, 4 de junio de 1741.

19.- A.H.N. Consejos. Leg. 18.250. Memorial de Tomás Cebrián.

20.- A.H.N. Consejos. Leg. 18.250. Representación del ayuntamiento de San Felipe.

21.- Su madre, Elena Cebrián, era hermana de José Cebrián, y ambos hijos de Félix Cebrián.

22.- A.H.N. Consejos. Leg. 18.250. Relación de méritos de Gaspar Cebrián de Cebrián. Madrid, 20 de febrero de 1745.

23.- Hacia mitad de la década de los cuarenta estaba "la ciudad exhausta de medios con que poderlo ejecutar", en A.H.N. Consejos. Leg. 18.250. Testimonio dado por Rafael Medina sobre el cabildo de 19 de septiembre de 1746.

24.- A.H.N. Consejos. Leg. 18.250. Testimonio dado por Rafael Medina sobre el cabildo de 19 de septiembre de 1746 .

25.- A.H.N. Consejos. Leg. 18.250. Representación del Ayuntamiento de Orihuela. Orihuela, 4 de octubre de 1746.

26.- Idéntico planteamiento defendieron los regidores de San Felipe en 1741 y 1743, así como en 1764 cuando Tomás Cebrián traspasó dicho empleo a su hijo Francisco. Cfr. A.H.N. Consejos. Leg. 18.250. Testimonio dado por Luis Meliana del cabildo celebrado en 26 de octubre de 1764.

27.- A.H.N. Consejos. Leg. 18.250. Testimonio dado por Rafael Medina del cabildo celebrado en 4 de diciembre de 1746.

28.- Señalaba Gaspar Cebrián que "fue la gracia remunatoria (sic) y en paga de servicios, y por este motivo no puede tantearse el empleo, pues los méritos y servicios personales no tienen otro valor que el que admite la clemencia de S.M. de sus fieles vasallos", cn A.H.N. Consejos. Leg. 18.250. Representación de Gaspar Cebrián, 10 de noviembre de 1746.

29.- A.H.N. Consejos. leg. 18.250. Memorial de Ignacio Sánchez Belmont.

30.- A.H.N. Consejos. Leg. 18.250. Dictamen del fiscal de la Audiencia. Valencia, 16 de enero de 1747. 
31.- A.H.N. Consejos. Leg. 18.250. Consulta de la Cámara de Castilla de 26 de abril de 1747.

32.- A.H.N. Consejos. Leg. 18.250. Representación del Ayuntamiento de Orihuela. Orihuela, I 8 de julio de 1747.

33.- A.H.N. Consejos. Leg. 18.250. Consulta de la Cámara de Castilla de 23 de noviembre de 1746.

34.- A.H.N. Consejos. Leg. 18.250. Relación de servicios de Francisco García. Madrid, 20 de marzo de 1735.

35.- A.H.N. Consejos. Leg. 18.250. Consulta de la Cántara de Castilla de 20 de febrero de 1747.

36.- A.H.N. Consejos. Leg. 18.250. Consulta de la Cámara de Castilla de 19 de julio de 1747.

37.- A.H.N. Consejos. Leg. 18.338. Certificación dada por Francisco Ivorra, 9 de junio de 1735 . 